\title{
A Research on Mystic Alexa Mirror
}

\author{
Shivaputra, Meenakshi L Rathod, Shwetha M, S Soundeswaran
}

\begin{abstract}
The present works main motive is to design and build a mystic Alexa mirror that represents an elegant interface for glancing information for many people in any environment, for instance college, company etc. The device will look like a regular mirror but would have a screen inside and the user will be sensed automatically by the proximity sensor installed inside and it would interact with using voice commands.

In the case of college guide, the coding have been done in such a way that it can tell the details about that particular place by using a security camera as well as tell the directions for the classrooms, different blocks, labs, washrooms etc. Using Google assistant controlled display, the user can send messages to the mirror from his smart phone without using a sim card. And so this is how we will be able to achieve our main objectives by building this project.
\end{abstract}

Keywords: Internet of things, IDE, Application Program Interface, Wireless Fidelity, LED, Voice User Interface.

\section{INTRODUCTION}

Our project is within the context of a time where every day we see more and more connected devices. Mobile phones are elevated as smart phones and since then this concept has exploded and transformed into the Internet of Things (IoT) [3-5].

In IoT, the 'thing' could be an individual wearing a heart monitoring gadget or a car with sensors and these devices will be allotted an IP address and capable of gathering information and move data through a network without manual help or mediation.

The gadget constantly tunes in to all discourse, checking for the wake word to be verbally expressed, which is essentially set up as "Alexa" [1,2]

Echo Dot is a voice-controlled speaker that utilizes Alexa (virtual assistant) to play music, control home gadgets, make calls, answer questions, set clocks and alerts, shopping day and can get to Wikipedia articles.

Besides, it can also control lights, locks, thermostats, and more with compatible connected devices. It has usual, routine voices resulting from speech unit technology which is hands free and voice enabled gadget with a small inbuilt speaker. Highly refined NLP \& TTS algorithms attain better speech accuracy.

Echo Dot can receive your command across the room even while other noises or song is live.

Whenever you want to employ Echo Dot, just call the wake word "Alexa" and Dot answers instantaneously. It will

Revised Manuscript Received on December 30, 2019.

Shivaputra, Department of Electronics and Communication Engineering, Dr. Ambedkar Institute of Technology, Bengaluru-560056, Karnataka, India. (Email: Shivaputra@dr-ait.org)

Meenakshi L Rathod, Department of Electronics and Communication Engineering, Dr. Ambedkar Institute of Technology, Bengaluru-560056, Karnataka, India.

Shwetha M, Department of Electronics and Communication Engineering, Dr. Ambedkar Institute of Technology, Bengaluru-560056,

S Soundeswaran, Department of Chemistry, Dr. Ambedkar Institute of Technology, Bengaluru-560056, Karnataka, India. Karnataka, India.

also control several smart electrical appliances acting as a home automation hub.

\section{VOICE SYSTEM:}

The aim of this project is to combine the advantages of a smart phone and a mirror.

The features of our project includes weather forecast, play music or videos, local time corresponding to the location, college guide will be displayed in response to voice commands by the user.

The most interesting feature will be the ability of our product to sense the users who come near the monitor to avail the services provided by it.

This is done with the help of a proximity sensor and the LED bulbs are also provided which will glow soon after the user comes in front of the monitor.

Raspberry Pi 3 model B was used for all the computing required for this project. This includes the programming required for responses like showing the directions for the different blocks in college, laboratories, different departments etc. and apart from this, it will also give the weather forecast, time etc.

\section{OBJECTIVE}

The main objective of this project is to develop a college guide which will be very helpful for the students. As a proximity sensor will also be used, our project will prove to be very user-friendly because as soon the user comes in front of the mirror, the sensor will sense him or her and glow the LED bulbs indicating that it has sensed the user. The students just need to give voice commands like "Alexa, where is C block?", "Alexa, in which building is department of E\&C?" and likewise. The device will also be able to answer general questions like local time of the location, weather forecast and news \& headlines.We,asateamaremainlyconcernedinbuilding something that is useful and usable in real life, bymaking it as a commercially competitiveproduct.

\section{METHODOLOGY}

\section{A. Mystic Alexa Mirror as AMirror}

It functions very similar like normal one way mirror where one can view himself/herself.

\section{B. Mystic Alexa Mirror As an Information System}

A predefined online URL used to fetch details like Time, Date, weather and news. Also several websites are used to fetch news.

\section{Mystic Alexa Mirror As a Student Guide.}

Directions to the different department locations, 
important notifications about the college events like time, dates of internals andexternals examinations.

D. Mystic Mirror Website to dynamically change the data

The user can create an account and change the information dynamically without actually changing the code.

\section{STEPS INVOLVED}

Step 1: Scrolling display controlled by Google Assistant.

- $\quad$ Configuring Adafruit MQTT andIFTTT.

- $\quad$ Configuring google assistant throughIFTTT.

- $\quad$ Linking Adafruit MQTTT and Google Assistant throughIFTTT.

- $\quad$ Configuring the NODEMCU(CH340) using Arduino IDE.

- $\quad$ Connecting NODEMCU to LEDmatrix.

- $\quad$ Sending messages from Google Assistant and checking the output in the ledmatrix.

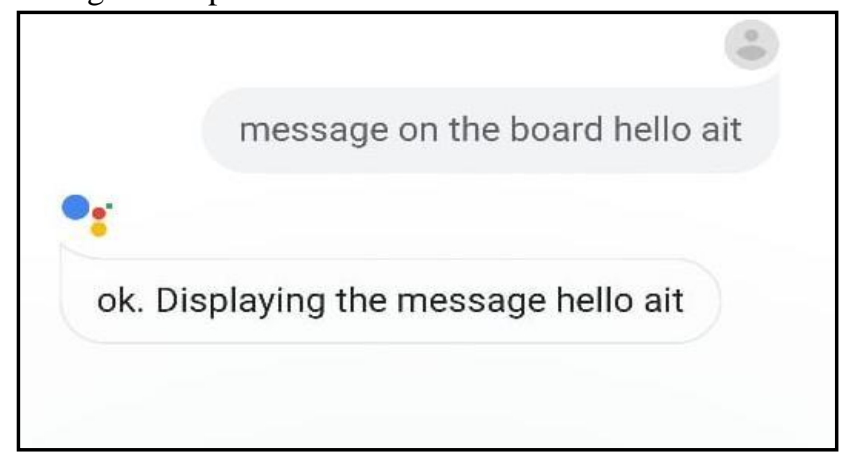

Google Assistant display

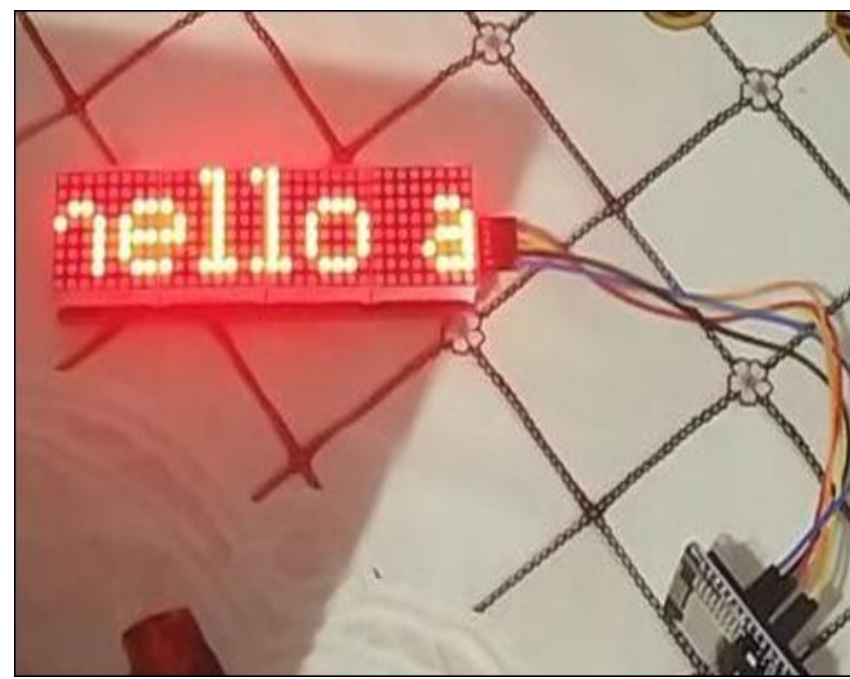

LED Matrix display1

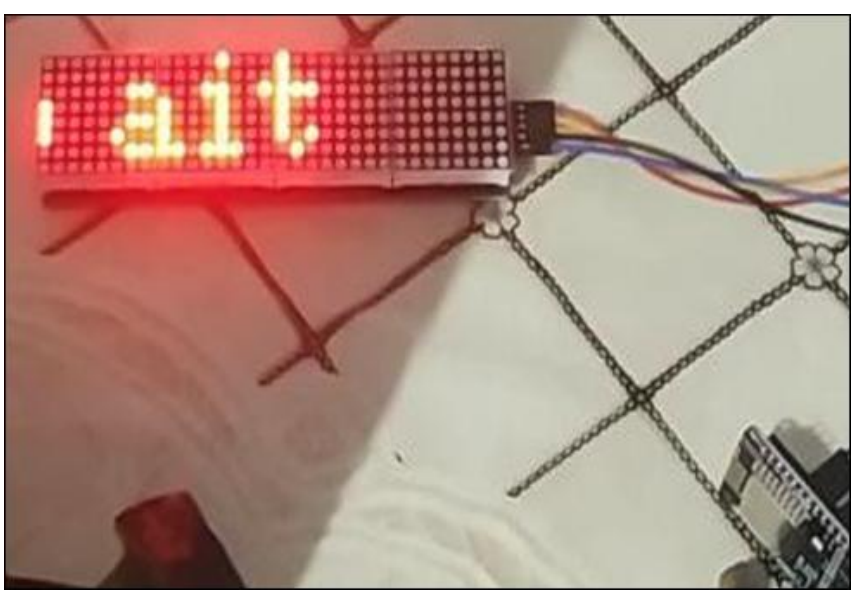

LED Matrix display2

Step 2: The Smart Mirror Setup

- $\quad$ Setting up OS for the raspberrypi:

Install Raspbian stretch file downloaded from Raspberry Pi official website into 16GB SD card.

- $\quad$ Connect the SD card into the RaspberryPi.

- Attach raspberry pi to the monitor and also connect keyboard and mouse with Pi and then power up the Pi.

- $\quad$ Once the raspberry pi boots up update the local time and language.

Enable SSH and VNC.

- Install Magic mirror software to thePi.

- $\quad$ Go to the Magic Mirror file and add desired location's time and weather details in thecode.

- $\quad$ Add other details like calendar, news updates, quotes, songsetc.

- Change settings such that Pi automatically reboots to MagicMirror.

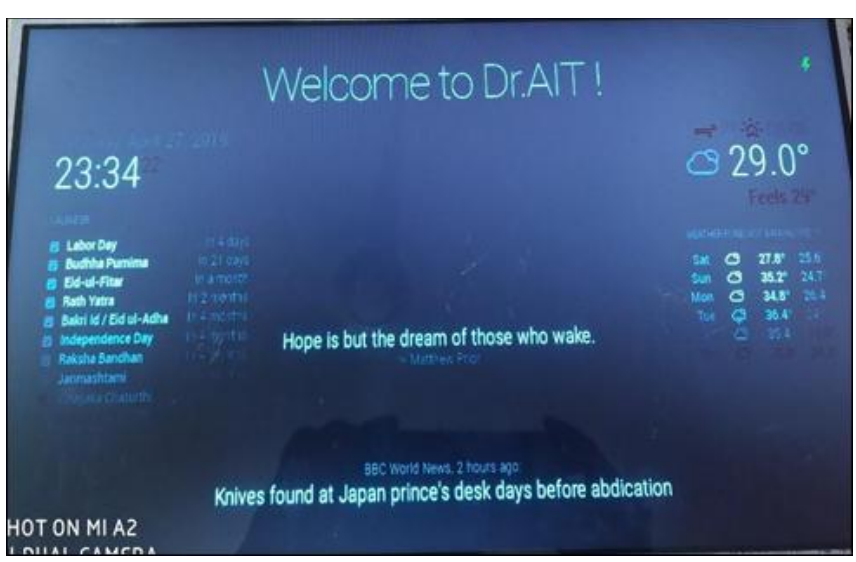

Monitor display

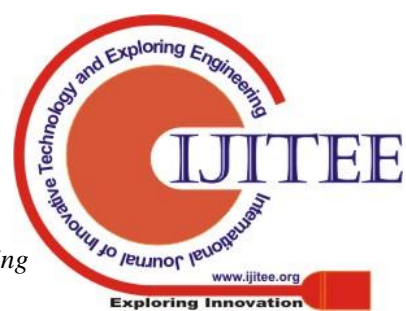




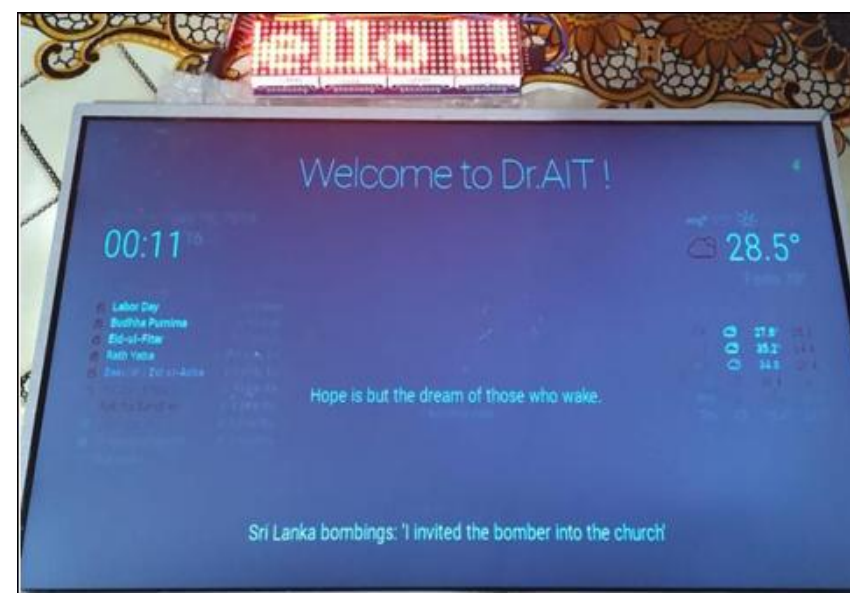

Monitor with LED display1

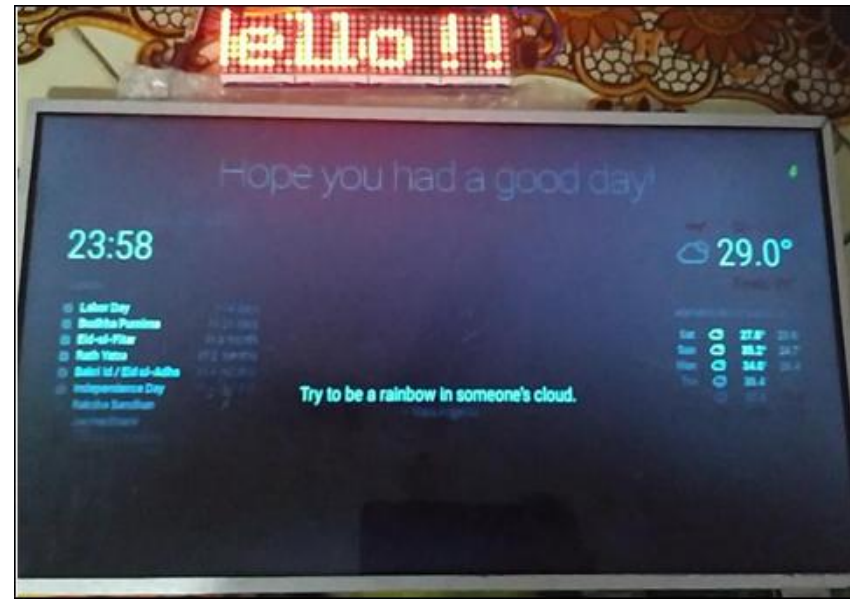

Monitor with LED display2

Step 3: Alexa Skills:

Creating the Alexa Skill.

1. Go to "Alexa Skills Kit", move to "Add newskill"

2. Choose a Name and Invocation, then "Save", "Next"

3. Go to "Launch Skill Builder" which is Next to "Intents", choose"ADD"

5. In custom intent, enter "Count Intent" and choose "Create Intent"

6. Go to, "Create New Slot", type "slot type" and "Add"

7. Underneath "slot type", select "Choose a slot type"; at the bottom, type slot type into "Create a New Slot Type" and click"+"

8. Open developer.amazon.com, sign in, and click the Alexatab

9. Underneath "Sample Utterances", go to "slot type" and pressEnter

10. In "Slot Types", go to "Website"

11. Underneath "Slot Values", enter a new value "Amazon.com" and select "+";for adding a few more websites

12. Select "build model" at the top of the page

13. Once it is completed, click "Configuration"

14. "Create the Lambda function"

15. Test the skill in the "Enter Utterance" box, then click "Ask"

16. If the tests pass, then proceed toPublish.

Creating the LambdaFunction.
Initially, to handle the Alexa requests a Lambda Function has to be created. This sample will ask the user to provide a URL, sends it to the share counts algorithm.

1. Open aws.amazon.com.

2. Under "AWS services", search for (andclick) "Lambda"

3. Select "Create a LambdaFunction"

4. Select create fromScratch.

5. check the empty square and choose "Alexa Skills Kit", then click"Next"

6. Choose a name, and select "Node.js 6.10" asyour runtime.

7. Type thecryptogram.

8. Underneath the code block, pick "create a custom role"

9. In the automatic window, keep the defaultvalues ("lambda basic execution"); click"Allow"

10. Go back to main window, click "Next", "CreateFunction"

11. Once it created, an ARN will appear. Copy the value startingwith "arn:aws:lambda:"

12. Proceed to "Creating the Alexa Skill".

Step 4: Mystic Mirror Website

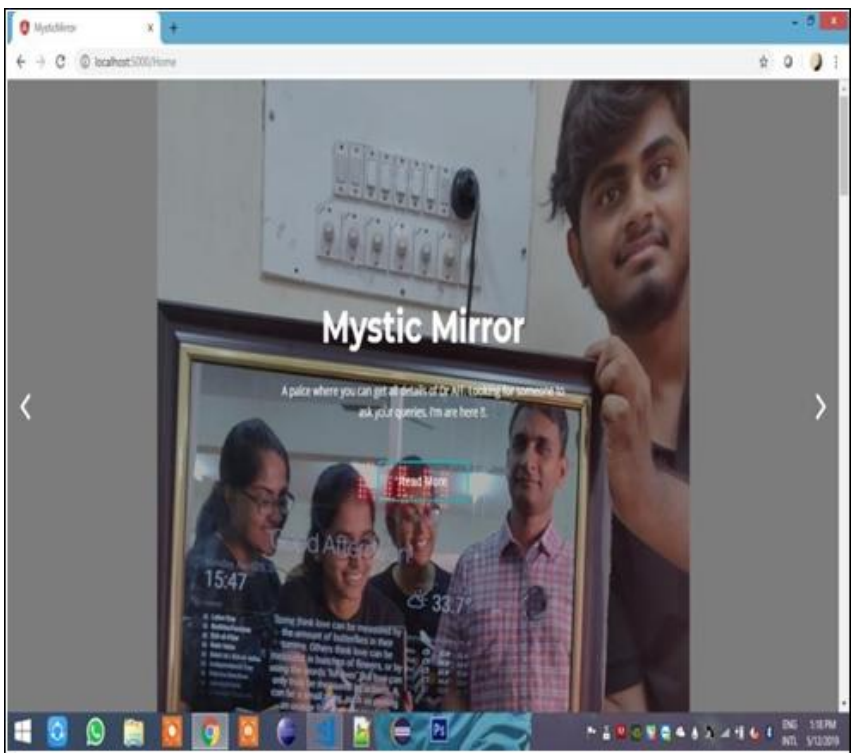

Web interface 


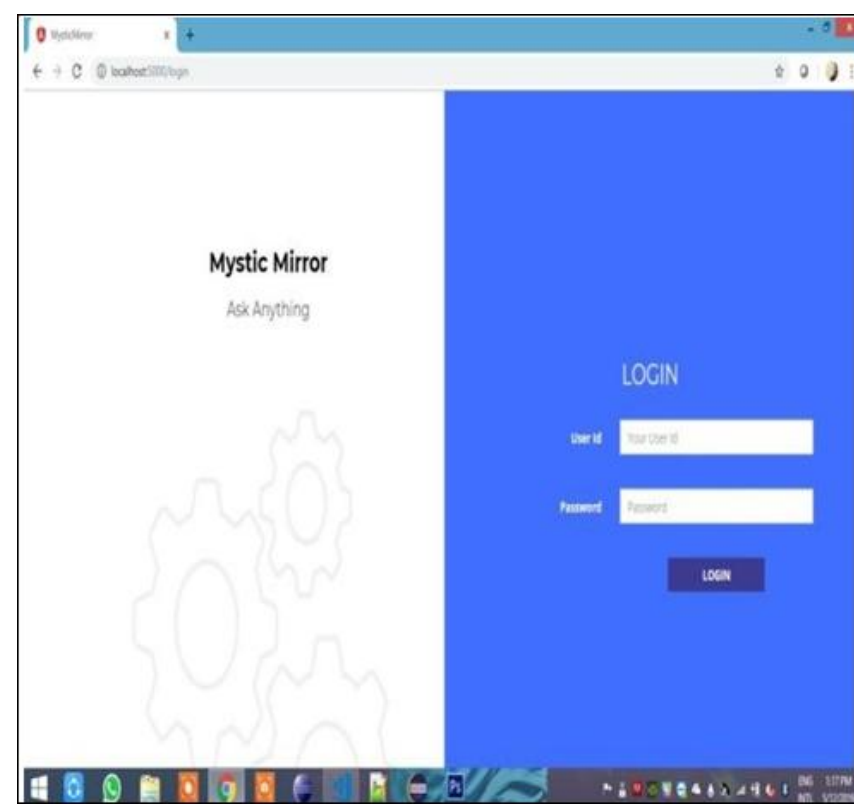

Mystic mirror login page

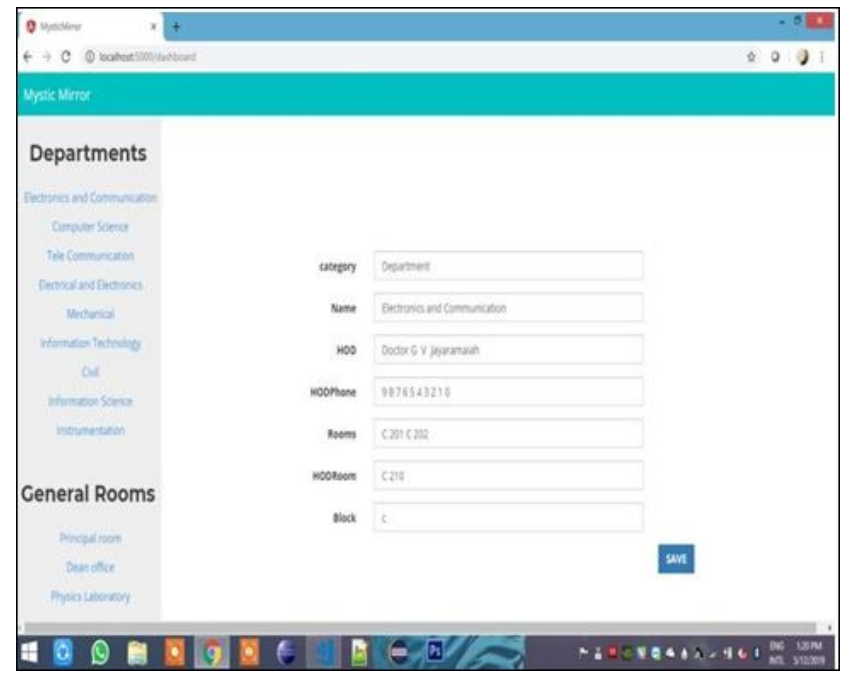

Dynamic data change

Step 5: Fabrication.

A wooden frame was attached to the two-way mirror and then the monitor was fixed to the back of the frame. To this setup, all the components were firmly placed using a cello tape. Lastly the power supply was provided.

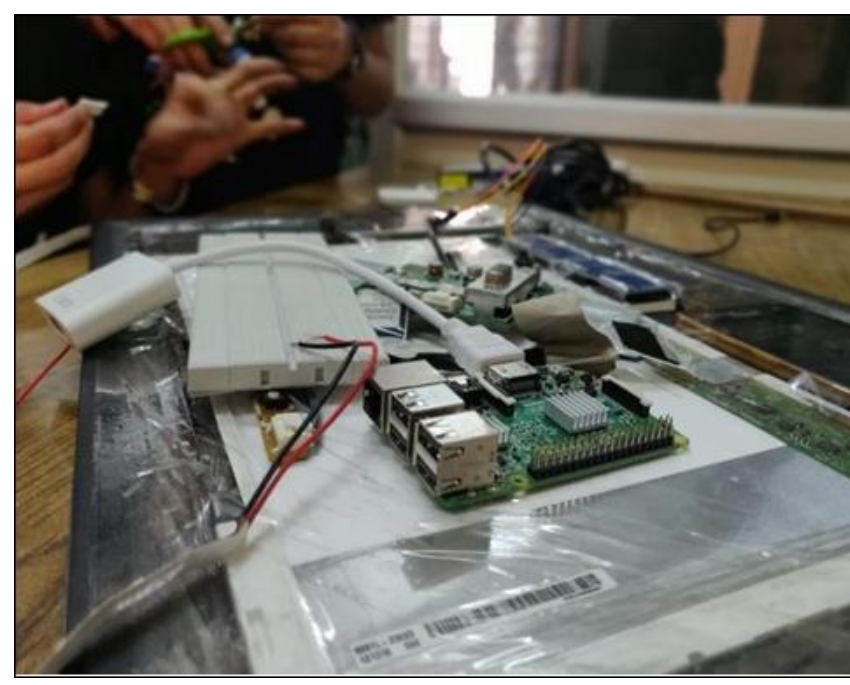

Fabrication
Step 6: Final setup and finish.

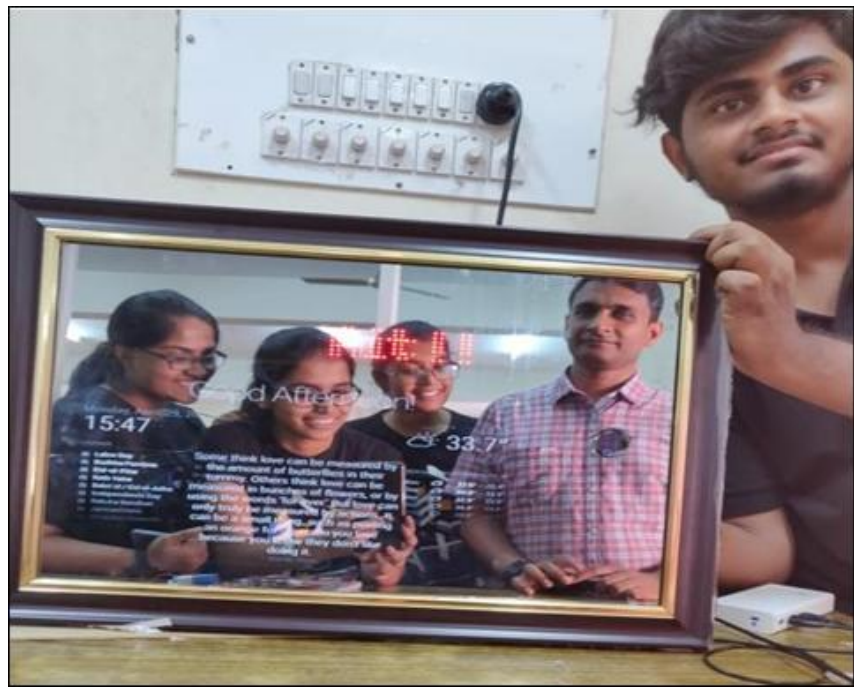

Mirror final setup

\section{BLOCK DIAGRAM}

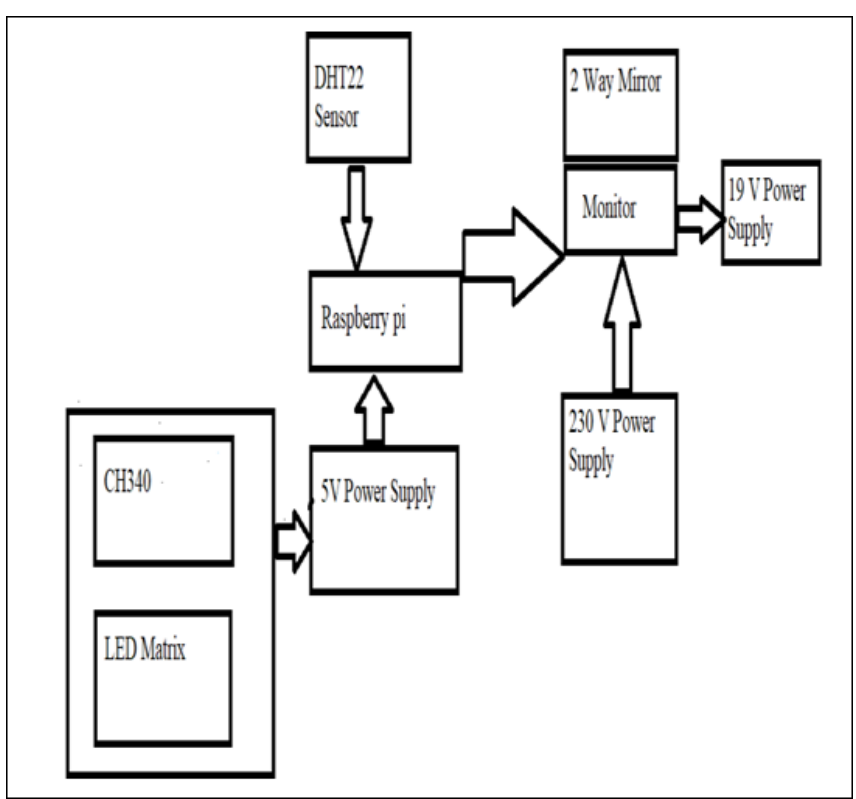

\section{WORKING\& RESULTS}

The aim of designing this model is to create an interactive interface which can be conventionallyused. Various services like weather; calendar, news, stock updates etc can be accessed and controlled using voice commands.

The mirror is eventually a technically improved interactive gadget. The target of the project was designing the mirror to provide a characteristic interface in nature for accessing various services. We designed and developed a futuristic smart mirror based on Raspberry pi and fabricated a working prototype.

Mirror is common household and the concept of smart mirror which is interactive with human is attractive and can be fantasized by anyone. Sometimes people doesn't have

Published By:

Blue Eyes Intelligence Engineering \& Sciences Publication

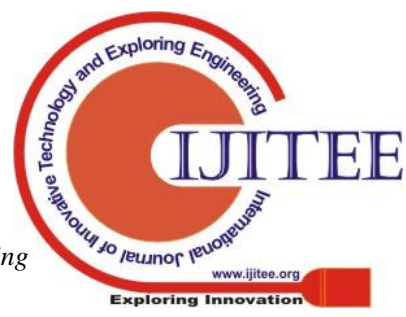


time to read newspaper or watch television to check climate report or breaking news. If a customary mirror acts as gadget, one can envision the measure of time it will spare and be of such an incredible use.

The project which would gather real world data such as location based latest news, headlines, weather reports, and as well as show us the local time. A central database will manage all the data which is transmitted from the machine.

We have also worked on including Artificial Intelligence in the Smart Mirror wherein a voice enabled assistant will cater to the needs of the user. In spite of using Echo Dot, we have built a Google Assistant controlled display also, wherein a user can send messages to the mirror, in case of any emergency and it does not even require a Sim Card. This product is also equipped with a secret security camera using which we will be able to monitor home or at any particular place where the mirror is installed.

\section{ANALYSIS AND COMPARISONS}

\begin{tabular}{|c|c|c|c|}
\hline \multicolumn{4}{|c|}{ Comparisontable: } \\
\hline $\begin{array}{l}\text { PROPERTI } \\
\text { ES }\end{array}$ & $\begin{array}{l}\text { EXISTING SMART } \\
\text { MIRROR }\end{array}$ & $\begin{array}{l}\text { EXISTINGECHO } \\
\text { DOT }\end{array}$ & $\begin{array}{l}\text { MYSTIC ALEXA } \\
\text { MIRROR }\end{array}$ \\
\hline $\begin{array}{l}\text { UI \& Voice } \\
\text { system }\end{array}$ & $\begin{array}{l}\text { Provides both display and } \\
\text { speech. The user has to } \\
\text { create an account in order } \\
\text { to use it. }\end{array}$ & $\begin{array}{l}\text { NLP algorithm is } \\
\text { used for speech } \\
\text { recognition but does } \\
\text { not provide display of } \\
\text { data. }\end{array}$ & $\begin{array}{l}\text { Provides both display } \\
\text { and speech but there is } \\
\text { no need to create an } \\
\text { account as its user- } \\
\text { friendly. }\end{array}$ \\
\hline $\begin{array}{l}\text { Facial \& } \\
\text { Voice } \\
\text { recognition }\end{array}$ & $\begin{array}{l}\text { Uses facial recognition to } \\
\text { distinguish between } \\
\text { different users, but it } \\
\text { always requires good } \\
\text { lighting conditions. }\end{array}$ & $\begin{array}{l}\text { Provides voice } \\
\text { recognition using } \\
\text { AVS (Amazon Voice } \\
\text { Service). }\end{array}$ & $\begin{array}{l}\text { Does not require both } \\
\text { and can be used by } \\
\text { anyone. }\end{array}$ \\
\hline $\begin{array}{l}\text { Skills } \\
\text { Updation }\end{array}$ & $\begin{array}{l}\text { Requires the change of } \\
\text { code using bulky } \\
\text { components like monitor } \\
\text { and keyboard, which is } \\
\text { tedious. }\end{array}$ & $\begin{array}{l}\text { Amazon allows } \\
\text { developers to build } \\
\text { and publish skills for } \\
\text { Alexa using the } \\
\text { Alexa app. }\end{array}$ & $\begin{array}{l}\text { The fed data can be } \\
\text { dynamically changed } \\
\text { using the mystic mirror } \\
\text { website. }\end{array}$ \\
\hline Cost & $\begin{array}{l}\text { High quality camera is } \\
\text { used for facial } \\
\text { recognition, thereby } \\
\text { increasing cost. }\end{array}$ & $\begin{array}{l}\text { Does not require } \\
\text { facial recognition, so } \\
\text { is comparatively less } \\
\text { costly than smart } \\
\text { mirror. }\end{array}$ & $\begin{array}{l}\text { Less expensive } \\
\text { compared to both as it } \\
\text { was made from scratch. }\end{array}$ \\
\hline
\end{tabular}

\section{CONCLUSION \& FUTURE} ADVANCEMENTS

\section{CONCLUSION}

A completely automated Mystic Alexa Mirror represents sophisticated interface for glancing information for various people in any surroundings, such as college, company.

The designed and fabricated gadget will have a screen inside but it will look like a regular and it is enabled to interact with the user using voice commands.

Our developed product capable of providing the basic common information such as weather of the city, latest updates and local time corresponding to the location.

And it also acts as a student guide providing information about thecollege.

\section{FUTURE WORK}

The present work will be explored or extended further in other environments by using new technologies. The state of innovation is to provide more information with less interaction to get it. This device will resolve many problems of the students in campus and hostel in colleges or any other institution. Apart from this, it has applications in the automotive industry, consumer -household applications, medical - healthcare and Advertising - Retailindustry.

\section{REFERENCES}

1. Bohn, dieter "You can finally say computer to your echo to command it". Retrieved 2017-01-28.

2. "Amazon Alexa". Alexa.amazon.com. Retrieved 2016-08-02.

3. Bjose.Jane et al. "Home Automated Smart Mirror As An Internet Of Things (IOT) Implementation".

4. Speech technology media". Star performers: Amazon's on fire". Retrieved. https://en.wikipedia.org/wiki/Amazon_Echo.

5. "Amazon.com Help: Set Up Your Amazon Echo". Amazon.com. Retrieved 2015-03-04. 